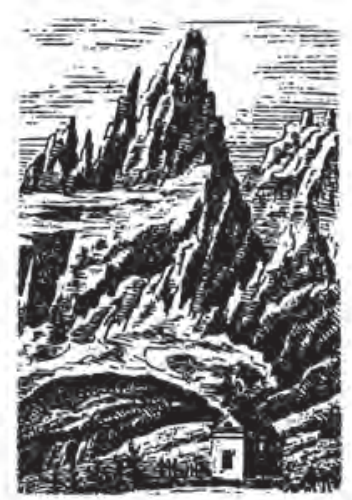

Ksenia Stanicka-Brzezicka

ORCID: 0000-0003-2390-8903

Herder-Institut für historische 0stmitteleuropaforschung —

Institut der Leibniz-Gemeinschaft

ksenia.stanicka@herder-institut.de

https://doi.org/10.19195/2084-4107.13.23

\title{
Ikonosfera kurortu górskiego. Przyczynek do studiów nad historią uzdrowisk śląskich w XIX i XX wieku
}

Słowa-klucze: turystyka, uzdrowisko, informacja wizualna, reklama, Śląsk

Keywords: tourism, resort, visual information, advertising, Silesia

\section{The iconosphere of the mountain resort. A contribution to the study of the history of Silesian resorts in the 19th and 20th centuries}

Summary

One of the phenomena within the cultural construct created around the mountains was from the beginning of the nineteenth century the rise of resort culture. An extremely important element of this emerging resort culture was the development of iconography (pictorial representations), which - having originated in painting and then growing thanks to the spread of graphic techniques and 
the industrialisation of reproduction technologies — became a mass-scale phenomenon. Tourism began to generate a demand for various types of souvenirs and pictures made with the help of various techniques and materials (illustrated publications, engravings, photographs, postcards, dioramas as well as painted or engraved pottery or glass). It also became an impulse for the production of various components of resort culture, including advertising brochures and leaflets; posters and signboards, which became an increasingly familiar part of the urban iconosphere; shop windows; newspapers and magazines with advertising inserts; and even graphic layout of restaurant menus or hotel bills; finally, small architectural forms complementing big resort ensembles.

This phenomenon should be viewed in many contexts - social transformations, especially social reception of visual messages, growth of resorts, development of medicine, technical infrastructure and many other. So far research into resorts has focused largely on an earlier period, encompassing the nineteenth century. However, the first half of the twentieth century has left a significant mark in the tourist space, and, above all, a lot of visual evidence. All this - from the oldest, eighteenth-century voyages pittoresques to twentieth-century "modern" advertisements of places, sites and events - can be used as a basis for research into pictorial culture and its analyses.

Naturally, the mountains are one of the most important elements of this iconography. They are its main protagonist, sometimes a background or backstage. They are a real element of local topography or a symbol and archetype.

The phenomenon can be observed also in Silesia, in the resorts of the Giant Mountains and the Kłodzko Valley, also in Polanica, when a joint-stock company was set up to manage and expand the resort.

The article presents the components and history of increasingly professional marketing strategies pursued by the local authorities and management of the various mountain resorts in Silesia from the nineteenth century until the first half of the twentieth century. In addition, the author analyses image as a form of message as well as the power of visual information in the context of reflections on the popularisation of the mass media and information explosion, researched today within the framework of visual sociology, visual anthropology and visual culture studies.

Pod koniec XIX wieku oficyna wydawnicza „Graphische Kunstanstalt Hyll \& Klein” z ówczesnego Barmen kierowała do władz miasta Duszniki swą ofertę, w której zwracała się do włodarzy śląskiego uzdrowiska w słowach:

we współczesnej reklamie jest bezsprzecznie koniecznym i pożądanym dla osiągnięcia sukcesu, aby zalety miejscowości czy jakiegoś zakładu przekazać odbiorcy nie tylko słowami, ale przede wszystkim aby przez wyśmienity i odpowiadający rzeczywistości obraz urzeczywistnić w oczach odbiorcy interesujące położenie czy wspaniałe założenia architektoniczne. Takie obrazy nie tylko ułatwiają percepcję słów, one oddziaływują o wiele bardziej; słowo pozostawia namalowanie rzeczywistości wyobraźni każdego, obraz pokazuje jasno i wyraźnie zalety otoczenia ${ }^{1}$.

Usługodawca - tu wydawnictwo - w eleganckiej, rozbudowanej czy wręcz kwiecistej formie próbuje w ten sposób dotrzeć do potencjalnego klienta, jakim w tym przypadku są odpowiedzialne za promocję uzdrowiska jego władze, i prze-

1 Archiwum Państwowe we Wrocławiu, oddział w Kamieńcu Ząbkowickim (dalej: APK), akta miasta Duszniki, Brochuren über Bad Reinerz 1894-1899, sygn. 2126, s. 4. 
konać je do użycia obrazu jako formy przekazu. Ten jeden przykład wskazuje wyraźnie, że już wówczas zdawano sobie sprawę z siły wizualnej informacji.

Na przykładzie śląskich zdrojów, gdzie od XVIII wieku mamy do czynienia z rozwojem ruchu turystycznego, można jednak wykazać, że geneza jakże aktualnego i współczesnego procesu budowania nie tylko oferty turystycznej, lecz także - używając współczesnego języka — opartej na wizualizacji strategii marketingowej sięga co najmniej końca XVIII stulecia.

Turystyka zaczęła generować popyt na różnego typu pamiątki i obrazy, kształtował się fenomen kultury zdrojowej, a wraz z tym następował rozkwit ikonografii poświęconej zdrojom. Do wytworów, które moglibyśmy określić jako „ikonograficzne” - czyli posługujące się obrazem - zaliczymy wyposażone w ilustracje publikacje, grafiki, fotografie, pocztówki ${ }^{2}$, dioramy ${ }^{3}$, foldery i ulotki reklamowe, plakaty, różnorakie szyldy i plakaty zadomawiające się w miejskiej ikonosferze, sklepowe witryny, gazety i czasopisma z reklamowymi inseratami, a nawet graficzną oprawę restauracyjnych menu czy rachunków hotelowych, po wszelkiego rodzaju, wykonane w różnych technikach i materiałach souvenirs, czy wreszcie rozbudowę i uzupełnienie o elementy tak zwanej małej architektury wielkich, zdrojowych ensembles.

Góry były naturalnie jednym z głównych elementów tej ikonografii. Były jej głównym bohaterem, czasami tłem, kulisą i to zarówno dla architektury, jak i, szczególnie we wcześniejszym okresie, scen rodzajowych (mówimy tu o tak zwanym sztafażu). Albo inaczej: mogły być realnym — niezależnie czy bardziej naturalistycznie, czy idealistycznie - przedstawionym elementem lokalnej topografii bądź symbolem i archetypem.

Skala i poziom tego zjawiska $\mathrm{w}$ odniesieniu do śląskich zdrojów zasługują jednak na szczególną uwagę. Znaleźć można wprawdzie opinie, że reklama istniała od starożytności, jednak w sensie profesjonalnym jej rozwój wiąże się z rozwojem społeczeństwa konsumpcyjnego w ostatnich dekadach XIX wieku, kiedy to jednym $\mathrm{z}$ podstawowych problemów staje się regulacja i stymulacja mechanizmów popytu i podaży. Teoretyczne podstawy reklamy oraz wiedza o jej metodach i środkach definiowane były jednak dopiero na początku XX wieku. Na gruncie niemieckojęzycznym pionierem w tej materii był Austriak Viktor Mataja (1857-1934), autor sztandarowego dzieła Die Reklame. Eine Untersuchung über Ankündigungswesen und Werbetätigkeit im Geschäftsleben, którego pierwsze wydanie ukazało się w $1910 \mathrm{roku}^{4}$. W następnych latach nastąpiła ekspansja podobnych wydawnictw, przede wszystkim w Stanach Zjednoczonych ${ }^{5}$. O wszech-

2 Por. P. Banaś, Orbis pictus. Świat dawnej karty pocztowej, Wrocław 2005, s. 199.

${ }^{3}$ Zob. A. Marsch, Popularność uzdrowisk i pamiatki, [w:] Dioramen. 3D-Schaublider der 19. Jahrhundert aus Schlesien und Böhmen / Dioramy. Trójwymiarowe obrazy XIX wieku ze Ślaśsa $i$ Czech, Hamburg 2005, s. 82-89.

${ }^{4}$ Duncker \& Humblot, potem wielokrotnie wznawiane.

5 Zob. np. L. Larned, Illustration in Advertising, New York 1920; H. de Bower, Advertising Principles, New York 1921. Także w Polsce O. Langer, Zasady ogłaszania, Warszawa 1927; M. Konieczny, Reklama. Poradnik w sprawach nowoczesnej kupieckiej reklamy: podręcznik dla szkót 
obecności reklamy współcześnie, a także znaczeniu działań definiowanych dziś jako marketing miejsc (place branding, place marketing, place promotion), public relation czy identyfikacja wizualna, nie trzeba dziś nikogo szczególnie przekonywać. W ostatnich latach coraz częściej dostrzega się wręcz ich uciążliwość i wprowadza ograniczenia - w Niemczech przez statutową działalność służb konserwatorskich, w Polsce przez ustanawianie Parków Kulturowych, na których obszarze obowiązują zakazy i reguły dotyczące umieszczania nośników reklamowych i nośników informacji wizualnej.

Jednocześnie w ostatnim półwieczu obserwujemy zdecydowany rozwój empirycznych i teoretycznych studiów nad kulturą obrazu, wizualnych metod badawczych, wizualnych środków komunikacji i mediów oraz wszystkiego tego, czym zajmują się visual sociology, visual anthropology i visual culture studies. W 1972 roku Mieczysław Porębski podjął rozważania nad umasowieniem środków przekazu i eksplozją informacyjną, definiując pojęcie ikonosfery — wizualnego środowiska człowieka, całokształtu otaczających go obrazów ${ }^{6}$. W ramach badań podstawowych powstają liczne opracowania, dotyczące ikonografii miast ${ }^{7}$, popularne stają się badania nad pocztówką jako autonomicznym dziełem sztuki graficznej ${ }^{8}$. Dawna reklama długo była jednak przede wszystkim źródłem do badań nad historią gospodarczą i społeczną; obecnie coraz częściej uwagę poświęca się także jej walorom wizualnym 9 .

Przyglądając się środkom komunikacji, przede wszystkim obrazom i technikom obrazowania, jakie towarzyszyły rozwojowi śląskich kurortów, można postawić tezę, że zjawiska te mogą być interpretowane jako wczesna faza profesjonalizacji miejskiej reklamy i środków służących kreowaniu wizerunku miejscowości.

Od XVIII wieku miejscowości dysponujące naturalnymi czynnikami leczniczymi, do których zalicza się wody mineralne oraz właściwości klimatyczne, w pełni przeistaczają się w kurorty, a wraz z licznymi pensjonariuszami zmienia się oblicze miejscowego krajobrazu ${ }^{10}$. Kurorty stają się po prostu modne, a coroczne w nich pobyty należą do zasobu typowych form życia towarzyskiego - najpierw wyższych, a później, w ramach procesów demokratycznych, i średnich sfer.

zawodowych. Wiadomości ogólne, podstawy psychologiczne, ogłoszenia gazetowe, list reklamowy, prospekt, broszura, katalog, Poznań 1938.

6 M. Porębski, Ikonosfera, Warszawa 1972.

7 Zob. np. E. Gwiazdowska, Widoki Szczecina. Źródta ikonograficzne do dziejów miast od XIV wieku do 1945, Szczecin 2001; trzytomowa Ikonografia Wrocławia, red. P. Łukaszewicz, oprac. E. Halawa, Wrocław 2008.

${ }^{8}$ Zob. np. P. Banaś, op. cit.; R. Jaworski, Alte Postkarten als kulturhistorische Quellen, „Geschichte in Wissenschaft und Unterricht" 51, 2000, nr 2.

9 Zob. np. M. Mrugalska-Banaszak, Miejska ikonosfera na drukach reklamowych $w$ widokami Poznania (1835-1939), Poznań 2012.

10 A. Herzig, Śląsk w pierwszej połowie XX wieku, [w:] Podróże w czasie. Dawne widoki Ślaska na grafikach z kolekcji Haselbacha [Zeit-Reisen: historische Schlesien-Ansichten aus der Graphiksammlung Haselbach], z tekstami A. Marsch, J. Brade, D. Codogni-Łańcuckiej, A. Herziga, H. Wańka, Wrocław 2007, s. 37. 
Pierwsze przewodniki po uzdrowiskach - co ciekawe z dzisiejszego punktu widzenia - pisane były często nie przez historyków czy znawców regionu, ale przez lekarzy lub innych pracowników uzdrowisk. Mimo to znajdują się w nich nie tylko passusy i objaśnienia związane z medycznymi aspektami kuracji, regulaminy uzdrowisk czy wiadomości ogólne z zakresu zdrowego trybu życia, lecz także informacje o ,instytucjach służących towarzyskiej rozrywce i zabawie kuracjuszy"11, o historii miejsca czy wreszcie propozycje tras wycieczkowych po okolicy. W 1821 roku lekarz Wilhelm Ludwig Schmidt, członek Śląskiego Towarzystwa Kultury Ojczyźnianej, wydał książkę Warmbrunn und seine Heilquellen $^{12}$. Tenże Schmidt, jako prawdziwy homo universalis, wykonywał też rysunki, które wydał między innymi w publikacji Die Ruinen des Kynast ${ }^{13}$. W tym samym roku ukazała się publikacja śląskiego mineraloga, rysownika i pisarza, profesora Królewskiej Akademii Rycerskiej w Legnicy, Carla Friedricha Moscha Die Heilquellen Schlesiens und der Grafschaft Glatz z dziesięcioma rycinami, do których autor sam wykonał podkłady rysunkowe; przygotowanie grafik zlecił zaś Johannowi Rossmäslerowi z Drezna ${ }^{14}$. W 1859 roku Christian Beinert, aptekarz w Jedlinie, opublikował własnym sumptem ilustrowany litografiami przewodnik Charlottenbrunn als Trink- und Badekur-Anstalt nebst Beschreibung der nächsten Parkanlagen ${ }^{15}$. W XX wieku przewodniki ukazywały się już dość licznie ${ }^{16}$. Wydawane były najczęściej przez zarząd uzdrowiska (Badeverwaltung) lub przez stowarzyszenia, takie jak na przykład założony 1908 roku Związek Kurortów i Letnisk Hrabstwa Kłodzkiego (Verband der Kurorte und Sommerfrischen in der Grafschaft Glatz) ${ }^{17}$; zawierały informacje historyczne, medyczne, dotyczące klimatu, położenia; opis oferty kulturalnej i rozrywkowej, możliwych wycieczek po okolicy, najczęściej również reklamy hoteli i pensjonatów. Opatrzone były ilustracjami graficznymi lub fotograficznymi, które dziś są świadectwem nie tylko ówczesnego wyglądu ulic, placów czy parków, lecz także wnętrz budowli - tych reprezentacyjnych, jak pijalnie, hotelowe foyers, teatry czy kawiarnie, ale i tych, które służyły zabiegom. Warto również zwrócić uwagę na szatę graficzną

11 B. Preiß, Der Kurort Warmbrunn, seine warmen Schwefelquellen und die ihren zugehörigen Heilanstalten. Ein Führer und Leitfaden für den Kurgast, mit besonderer Rücksicht auf Diätik, Wrocław 1850, s. 80, 146, w polskim tłumaczeniu cyt. za: A. Marsch, Widoki Śląska od roku 1493 do końca XIX wieku a kolekcja Haselbacha, [w:] Podróże w czasie..., s. 276.

12 W.L. Schmidt, Warmbrunn und seine Heilquellen, Hirschberg 1821.

13 W.L. Schmidt, Die Ruinen von Kynast, Hirschberg [ok. 1823].

14 C.F. Mosch, Die Heilquellen Schlesiens und der Grafschaft Glatz, Breslau-Leipzig 1821.

15 C. Beinert, Charlottenbrunn als Trink- und Badekur-Anstalt nebst Beschreibung der nächsten Parkanlagen, Charlottenbrunn 1859.

16 Zob. np. Kur-Bad Altheide in der Grafschaft Glatz, Provinz Schlesien. Mächtige Kohlensäure-Sprudel und weitere Moorlager gegen Herz-, Stoffwechsel- und Frauenkrankheiten, [Altheide] 1910; Bad Salzbrunn in Schlesien. Heilkräftig bei Katarrhen, Asthma Gicht, Nierenleiden, Görlitz [ok. 1930]; Bad Kudowa in Schlesien. Das Heilbad für Herz Basedow Nerven- und Frauen Leiden, Görlitz [1931].

17 APK, akta miasta Duszniki, Akten betr.: Gebirgs-Vereins, t. 3, sygn. 1565, s. 11 - Aufruf. Bildung eines Verbandes der Kurorte und Sommerfrischen in der Grafschaft Glatz, 1908. 
wydawnictw. Te wcześniejsze, z początku XX wieku, zdobione są secesyjnymi ornamentami i obramieniami, późniejsze — wydawane po pierwszej wojnie światowej — są przykładami modernistycznego przełomu w typografii.

Równolegle z rozwojem zdrojów od XVIII wieku ma miejsce także rozwój malarstwa pejzażowego. Oba te zjawiska lokują się w obrębie nurtów sentymentalizmu, potem romantyzmu i wreszcie ruchu reformatorskiego przełomu XIX i XX wieku, określanego na gruncie niemieckim mianem Reformbewegung. Fenomen kultury zdrojowej spowodował jednak, że obok malarstwa (i rysunku) bardzo szybko rozwinęly się te techniki obrazowania, które są łatwo multiplikowane, czyli różne techniki graficzne, przede wszystkim małoformatowe, jak litografia, potem chromolitografia, wreszcie fotografia, światłodruk i pocztówka ${ }^{18}$. Pod koniec XIX wieku zatriumfowały ostatecznie leporello fotograficzne i karta pocztowa oraz nowe techniki drukarskie, między innymi fotolitografia.

Odbitki graficzne, sprzedawane często naklejone na barwne podkładki, realizowane były głównie jako „grafika pamiątkarska”, funkcjonująca, jak zauważył znawca historii fotografii Anton Holzer, „mocą powtarzalności i, w tych wąskich granicach, mocą różnorodności”19. Istotne znaczenie miał tutaj również rozwój kolekcjonerstwa, którego najlepszym przykładem jest prezentowana w ostatnich latach na kilku wystawach i opisana w katalogu pod znamiennym tytułem Podróże $w$ czasie $^{20}$ kolekcja Albrechta Haselbacha (1892-1979), której duża część obrazująca śląskie zdroje jest właśnie tym typem wydawnictwa (zob. ilustracja 1).

Widoki doczekały się również wydań zbiorowych, jak na przykład Wanderungen durch das Riesen- und Isergebirge ${ }^{21}$ wspomnianego już Carla Friedricha Moscha, opublikowany w cieplickiej oficynie braci Liedlów po raz pierwszy w 1845 roku, z trzydziestoma malowniczymi pejzażami w wersji czarno-białej, kolorowanej lub na barwionym papierze. Serie graficzne ukazywały się także w wydawnictwach wrocławskich ${ }^{22}$, berlińskich, drezdeńskich oraz licznych kowarskich: Friedricha Augusta Tittla, Carla Teodora Mattisa, skąd pochodzą tableau z widokami uzdrowisk w Świeradowie, Szczawnicy i Cieplicach, oraz Carla Juliusa Riedena i Ernsta Wilhelma Knippla ${ }^{23}$.

Wreszcie masowy rynek opanowała wprowadzona w 1870 roku przez niemiecką pocztę Rzeszy karta pocztowa, która wkrótce — oprócz spełniania swej podstawowej funkcji - stała się również obiektem kolekcjonerskim (zob. ilustracja 2).

18 Por. A. Marsch, Widoki Śląska od 1493 roku..., s. 83 n., w szczególności rozdziały: 3. Romantyzm i realizm: Między pięknem przyrody a rewolucją przemysłowa, s. 129-240; 4. Ilość a jakość: Od projektu artysty do produkcji masowej, s. 241-289.

19 Cyt. za: D. Codogni-Łańcucka, Musée imaginare, [w:] Podróże w czasie..., s. 76.

${ }^{20}$ Por. przyp. 10.

${ }^{21}$ C.F. Mosch, Wanderungen durch das Riesen- und Iser-Gebirge und durch die ihnen benachbarten Thäler: ein Leitfaden für Reisende durch diese Gegenden, Warmbrunn 1845.

${ }^{22}$ Zob. np. Sudeten Album. Die Schlesische Bäder und Ihre Umgebung. Nach Natur gezeichnet von F. Koska, Wrocław 1846-1862.

23 A. Marsch, Widoki Śląska od 1493 roku..., s. 276. 


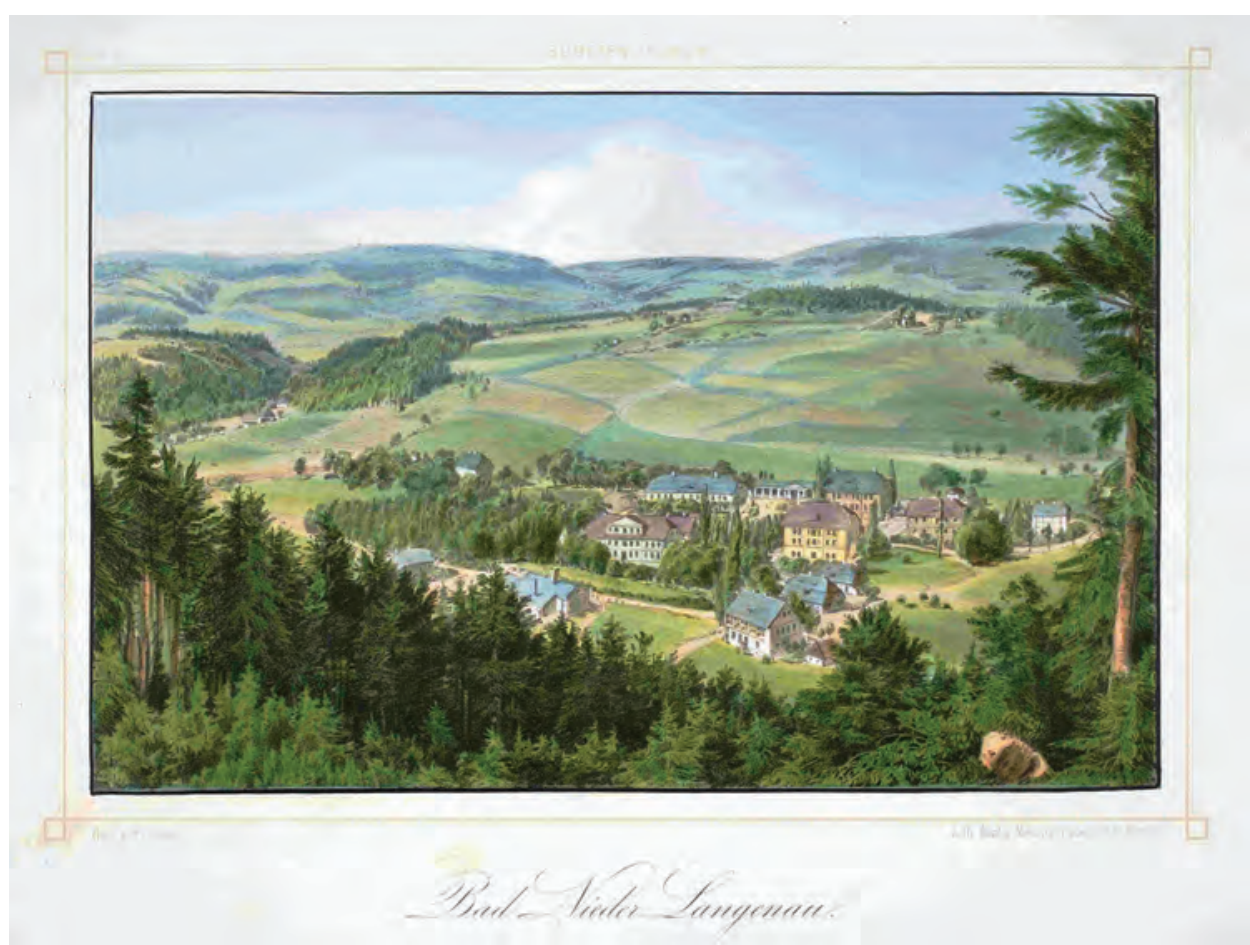

1. Długopole-Zdrój, widok ogólny, litografia kolorowana $25,1 \times 34,3 \mathrm{~cm}$, Sudeten-Album, 1848-1856, Bildkatalog Instytutu Herdera (Herder Institut) w Marburgu, nr inw. L 491

Rozwój turystyki zalicza się do czynników, które zadecydowały w istotnej mierze o rozpowszechnieniu kart pocztowych. Były one wykonywane wszelkimi dostępnymi metodami druku: chromolitografią, polegającą na odbijaniu poszczególnych kolorów z pojedynczych kamieni litograficznych, potem — po zastosowaniu w miejsce kamienia litograficznego płyty cynkowej lub aluminiowej — odpowiednio: cynkografią i algrafią. W 1879 roku pojawiły się pierwsze karty drukowane techniką światłodruku. Jeszcze przed 1900 rokiem produkowano karty techniką autotypii - druku wypukłego, w którym zastosowano klisze rastrowe, u progu zaś XX wieku najpoważniejsze miejsce w produkcji pocztówek miała oczywiście fotografia, która ostatecznie umasowiła ich produkcję ${ }^{24}$.

Znawca tematu, Paweł Banaś, kategoryzując karty pocztowe, wyróżnia pocztówki krajobrazowe ${ }^{25}$, do których zaliczymy pocztówki z uzdrowisk. Tego typu karty należały do najchętniej przesyłanych na przełomie XIX i XX wieku. Najpierw były to karty winietowe, jednostronne, o schemacie graficznym, w którym ilustracje - a dążono do pomieszczenia na karcie możliwie wielu interesujących widoków — usytuowane są przy górnej krawędzi oraz w lewym narożniku i zdobione różnorodnymi dekoracyjnymi ornamentami, eklektycznymi, potem secesyjnymi. W 1905

24 P. Banaś, op. cit., s. 20.

25 Ibidem, s. 54. 


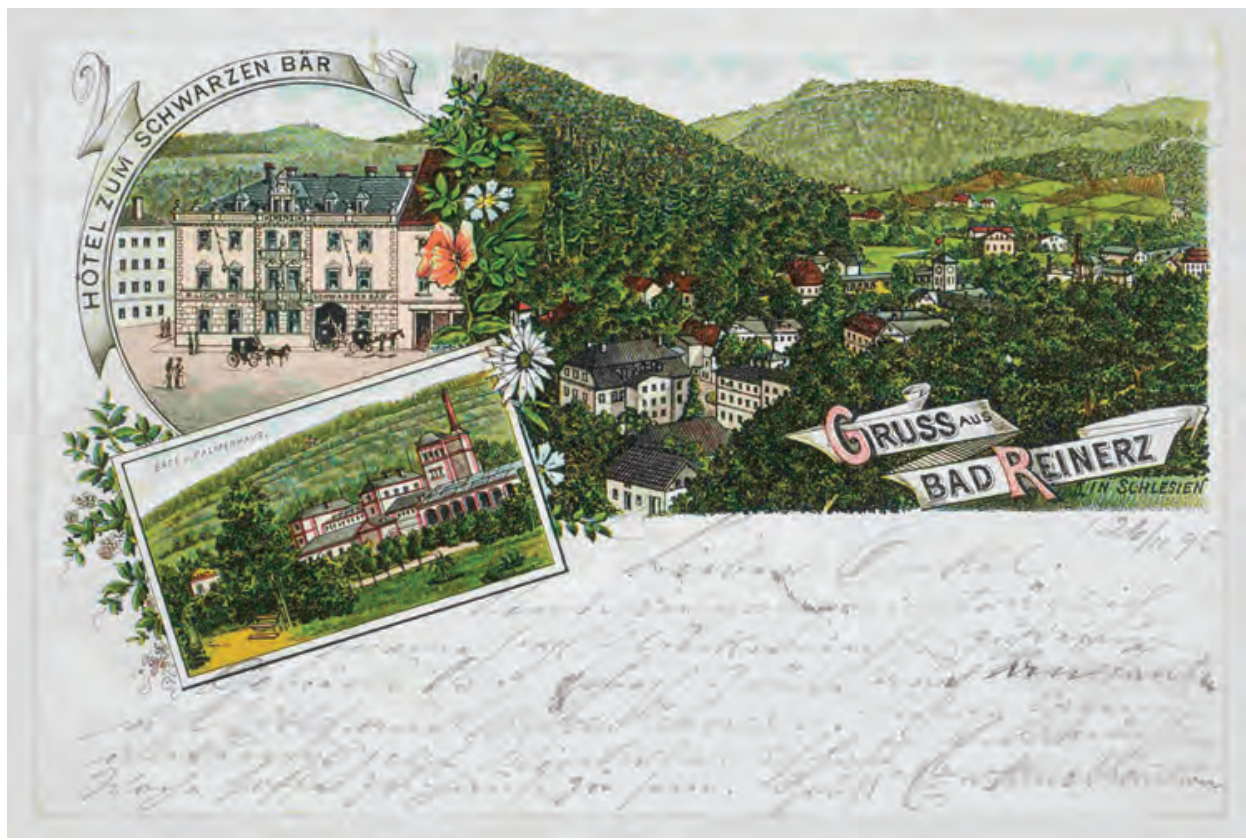

2. Duszniki-Zdrój, pocztówka $9 \times 14 \mathrm{~cm}$, przed 1895 rokiem, Bildkatalog Instytutu Herdera (Herder Institut) w Marburgu, Goettinger-Bildwerk, nr inw. 143785

roku wprowadzono podział strony adresowej na adres i miejsce przeznaczone na korespondencję; wkrótce potem wersje ograniczone do jednego obrazka.

Jednym z głównych oferentów pocztówek z widokami śląskich uzdrowisk było założone w 1884 roku w Cieplicach wydawnictwo artystyczne Maxa Leipelta, które oprócz leporellów oferowało kolorowe pocztówki artystyczne według prac śląskich malarzy pejzażystów, takich jak Carl Ernst Morgenstern, Friedrich Iwan czy Paul Aust ${ }^{26}$. W ogłoszeniu z 1926 roku wydawnictwo informowało o ofercie liczącej ponad 5 tysięcy motywów - mimo konkurencji na rynku utrzymywało czołową pozycję aż do końca drugiej wojny światowej (zob. ilustracja 3).

Dziś pocztówka historyczna cieszy się dużą popularnością — jest kolekcjonowana przez osoby prywatne i instytucje ${ }^{27}$, liczne albumy $z$ jej reprodukcjami wydawane są regularnie w wielu miejscowościach, tworzone są poświęcone jej wystawy, jak chociażby mająca miejsce w 2011 roku we Wrocławskiem Muzeum Narodowym wystawa „Grüss aus... Dolny Śląsk na dawnych pocztówkach”, z towarzyszącą jej publikacją Ikonografia Dolnego Ślaska: pocztówki ${ }^{28}$. W ramach tych zainteresowań pocztówka traktowana jest jako dokument historyczny, ale przed zbyt dosłownym jej odbiorem przestrzega cytowany już Paweł Banaś,

26 A. Marsch, Widoki Ślaska od 1493 roku..., s. 291.

${ }^{27}$ Liczny zbiór pocztówek o tematyce śląskiej, w tym zdrojowej, posiada Instytut Herdera w Marburgu.

28 Ikonografia Dolnego Ślaska: pocztówki, red. i oprac. R. Heś, Z. Bandurska, t. 1. BagieniecRzeczka, t. 2. Sady Górne-Żórawina Sudety, Wrocław 2011. 


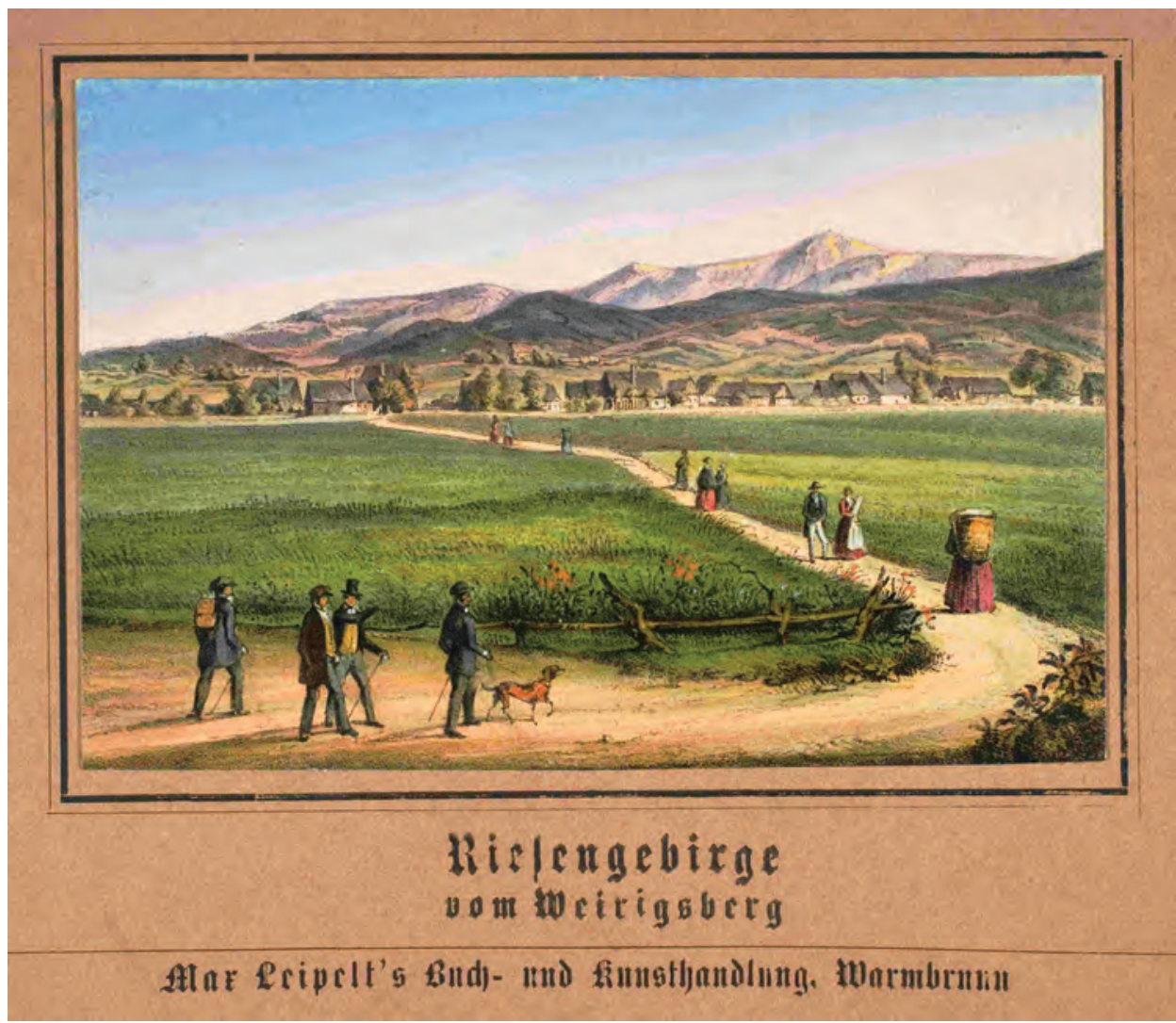

3. Karkonosze, widok ogólny, litografia kolorowana 15,1 $\times 17,8 \mathrm{~cm}$, Wydawnictwo Max Leipelt, Cieplice-Zdrój, Bildkatalog Instytutu Herdera (Herder Institut) w Marburgu, nr inw. P 1707

albowiem często miejscowość przedstawiona ulega „bardzo przemyślnym, wyrafinowanym zabiegom idealizacyjnym, także wówczas, gdy zachowano pozory obiektywnej relacji" 29 - i nie chodzi tu tylko o reprodukowane akwarele, romantyczne, stylizowane widoki — „daleko bardziej przewrotne w przeinaczaniu świata są jakby zakrzepłe w kadrze [...] sterylnie czyste przedstawienia budowli, ulic i placów z konwencjonalnym sztafażem”30. Nie uciekano także przed „fałszerstwami" w postaci kolaży.

Wybór motywów zdrojowych, sposób przedstawiania, charakterystyczne ujęcia w różnych technikach i czasie niejednokrotnie były już tematem rozważań, ostatnio chociażby w artykułach zamieszczonych w przytaczanej już publikacji Podróże w czasie. W odniesieniu do grafiki XVIII i XIX wieku najogólniej wyróżnić można widoki w perspektywie niejako „od zewnątrz” — czyli z oddali, gdzie sylwetka miejscowości zatopiona jest w zieleni, na pierwszym planie zaś pojawiać

29 P. Banaś, op. cit., s. 55.

30 Ibidem. 
się może sztafaż, najczęściej z postaciami spacerujących kuracjuszy — oraz „od wewnątrz" - z przedstawieniami fragmentów uzdrowiska, głównych założeń, budowli, małej architektury. Również tutaj „motyw kuracjusza” jest niezwykle popularny — eleganckie postacie niczym ,z żurnali zaludniają deptaki uzdrowisk sprawiających miejskie wrażenie" ${ }^{31}$. Dziś przedstawienia te są źródłem informacji na temat ówczesnej mody, wyposażenia i sposobów podróżowania.

Johanna Brade zwraca też uwagę, że w panoramach miast widoczne jest dążenie artysty do ukazania harmonii między przyrodą a postępującą urbanizacją ${ }^{32}$. Już w pierwszych dekadach XIX wieku w widokach miast zostały uchwycone zmiany związane $\mathrm{z}$ ich rozwojem - miejscowości ukazane są jako organizmy naturalnie wrośnięte w malowniczy krajobraz, bez murów miejskich. Częstym tematem są również założenia parkowe. Diana Codogni-Łańcucka zauważa daleko idące podobieństwo w wyborze motywów - wizerunki najpopularniejszych turystycznych celów układają się w ciągi niemal identycznych obrazów, zindywidualizowanych tylko szczegółami sztafażu lub niewielkim przesunięciem punktu obserwacji ${ }^{33}$. Wskazuje to na utrwalone wzory postrzegania — artyści aranżują to, co zobaczyli, w idealny, odpowiadający aktualnemu gustowi układ; turysta z kolei kupuje tylko takie przedstawienia, które ukazują poszukiwany motyw w sposób typowy, pozwalający na natychmiastową identyfikację. Chętnie przedstawiano również motywy z bezpośredniego otoczenia uzdrowisk, zarówno tych położnych w Kotlinie Kłodzkiej, jak i u podnóża Karkonoszy, lokalne atrakcje przyrodnicze (tu przede wszystkim „królową Karkonoszy” — Śnieżkę), ale i wiele innych, wśród których są na przykład: wzniesienie Trzmielak (Hummelsberg) koło Dusznik czy wodospad Kamieńczyka w Szklarskiej Porębie, oraz historyczne i architektoniczne, na przykład zamek Chojnik w pobliżu Cieplic.

Grafiki i pocztówki kupowane w miejscowościach zdrojowych „na pamiątkę rzeczywiście odbytej podróży, która zabierana do domu, skupia w sobie moc bezpośredniego przeżycia"34 były rodzajem souveniru. Pamiątki z podróży przybierały też inne formy, na przykład malowanych na kawałkach drewna widoczków czy dioram wytwarzanych w cieplickim warsztacie Liedlów. Jednym z najważniejszych asortymentów były jednak naczynia pamiątkowe: puchary, pucharki, szklanice, talerze i talerzyki, wazony, filiżanki, wykonywane od połowy XIX wieku z porcelany i szkła przez lokalnych wytwórców, między innymi fabrykę porcelany Carla Tielscha w Starym Zdroju, Carla Kristera w Wałbrzychu, Ohme w Szczawienku oraz huty szkła czynne w górskich rejonach Dolnego Śląska, na przykład Polanicy-Zdroju. Były one zdobione malowaną na porcelanie dekoracją, rytą i szlifowaną na szkle, na którym charakterystyczne zdobienie osiągano metodą tak zwanego szlifu diamentowego oraz matowym i polerowanym rytem. Uka-

31 J. Brade, „Piękny widok”: Idealizujace i romantyczne przedstawienia ślaskich miast, krajobrazów oraz przemystu od około 1800 do 1850/1860 roku, [w:] Podróże w czasie..., s. 54.

32 Ibidem.

33 D. Codogni-Łańcucka, op. cit., s. 76.

34 Ibidem, s. 75-76. 
zywano widoki miejscowości uzdrowiskowych z ich pijalniami, promenadami, kąpieliskami, teatrami, a także lokalnymi atrakcjami przyrodniczymi: pasmami górskimi, zamkami, wodospadami. Wzorem dla tych przedstawień były zwykle grafiki i rysunki. Kolekcje takich naczyń znajdują się dziś w muzeach regionu, Narodowym we Wrocławiu czy wałbrzyskim.

Co najmniej od drugiej połowy XIX wieku promocja uzdrowiska stała się przedmiotem profesjonalnie prowadzonych strategii marketingowych, realizowanych przez władze miejskie i kierownictwo poszczególnych uzdrowisk (zob. ilustracja 4). Wydawano foldery reklamowe, ulotki; zarządy uzdrowisk posługiwały się zdobionym papierem firmowym (na przykład papier firmowy „Bad Reinerz Badeverwaltung”35 czy „Reichgräflich Schaffgotsch'sche Badeverwaltung” z 1909 roku ${ }^{36}$. Zamieszczano informacje w prasie śląskiej ${ }^{37}$ i fachowej, jak na przykład w czasopiśmie „Die Medicinische Woche”, skąd pochodzą między innymi reklamy śląskich sanatoriów z 1902 roku $^{38}$, czy w „Allgemeine Deutsche Bäder-Zeitung" ${ }^{39}$, gdzie publikował sam ówczesny burmistrz i jednocześnie dyrektor uzdrowiska Duszniki, Paul Dengler ${ }^{40}$, który jest również autorem obszernej publikacji poświęconej historii miasta ${ }^{41}$.

Równocześnie o promocję dbają prywatni właściciele willi, pensjonatów, hoteli i restauracji, zlecając drukowanie reklam, ulotek, posługując się papierem firmowym ${ }^{42}$. Rozwinął się cały przemysł poligraficzny, oferujący zarówno sferze prywatnej, jak i publicznej produkcję materiałów informacyjnych. Wiele drukarni, zakładów fotograficznych czy tak zwanych „Kunstanstaltów” kierowało swoje oferty do władz miejskich, a liczba zachowanych tego typu świadectw pokazuje, że już wtedy rynek materiałów promocyjnych, operujących przekazem słownym i ikonograficznym, był dobrze rozwinięty. Zajmowały się tym i oferowały swoje usługi zarówno firmy lokalne, na przykład zakład fotograficzny Antona Josefa Schmidta z Dzierżoniowa, drukarnia Adolfa Sonnenburga z Cieplic, wydawca lokalnych gazet, jak i przedsiębiorstwa z daleka. Przykład tych ostatnich został już przywołany na wstępie, ale w zasobach śląskich archiwów można znaleźć ich więcej. Zachowana w aktach miasta Duszniki ulotka berlińskiej firmy Augusta Fuhrmanna, specjalizującej się w nowych wówczas mediach, takich jak panoramy czy obrazy stereoskopowe, które oglądane przez stereoskop sprawiają wrażenie

35 APK, Akta miasta Duszniki, Brochuren über Bad Reinerz 1910-1912, sygn. 2129, s. 282.

${ }^{36}$ Archiwum Państwowe we Wrocławiu (dalej: APW), akta majątku Schaffgotschów w Cieplicach, 1312-1945, Sect. II, Fach nr 24, 10 (1531).

${ }^{37} \mathrm{Na}$ przykład Ein Radiumbad in Bad Flinsberrg. Das dritte Radiumbad Deutschland errichtet, „Görlitzer Nachrichten” 9.06.1934, nr 133.

38 „Die Medicinische Woche” 20.02.2005.

39 Zob. np. „Allgemeine Deutsche Bäder-Zeitung” 4, nr 24.

40 P. Dengler, Schlesiche Bädertag, „Allgemeine Deutsche Bäder-Zeitung” 4, 1907, nr 24.

41 P. Dengler, Geschichte des Bades Reinerz, Reinerz 1903.

${ }^{42} \mathrm{Na}$ przykład papier firmowy hotelu J. Winter w Dusznikach, APK, akta miasta Duszniki, Bahnhofstr., sygn. 1628, s. 72; lub sanatorium dr Moehlisa, Archiwum Państwowe we Wrocławiu (dalej: APW), akta majątku Schaffgotschów w Cieplicach, 1312-1945, Sect. II, Fach nr 31, 10 (1621). 


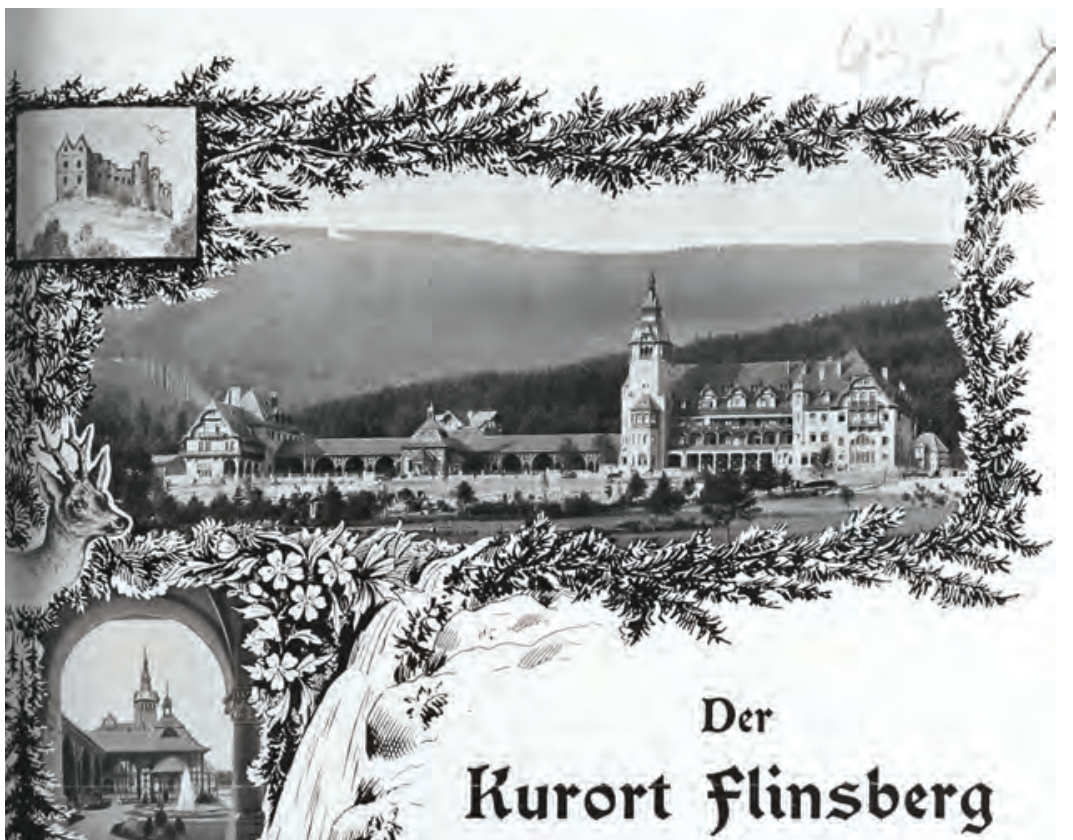

in der preupifchen provinz Schlefien gelegen befitz̧t Mineralquellen. welche feit etwa150 Jahren ihrer 5eilkraft wegen rühmlichit bekannt find.

flinsberg liegt mit feinen Kuranlagen an Hbbange des Jergebirges. $530 \mathrm{~m}$ über dem meeresipieget*) malerild fȫn von Bergzügen umgeben und berrlicher fernficht im nordoften auf den GreiffenItein (Bildchen links oben) mit [einen anliegenden Städten und Dörfern und füdöftlidh auf das wildromantildhe Queisthal mit dem 5odoftein.

Die Suft ift durds die in unmittelbarer Dähe fich ausdehnenden
adelholawaldungen vorzüglioh rein und aromatijo. Flinsberg ift daind

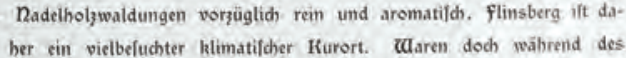
Jabres $1901 \mathrm{Mai}$ - October gegen gooo Derlonen anwelend. Der bedeutende Huffowwung, den flinsberg in den leţiten Jahrelj erlangt bat. ift wohl nicht zum Mindeften der neuen Kur-Anlage (liche obiges Bild) zuzulchreiben. Das Kurhaus ein impolanter Bail mit Concert- wnd

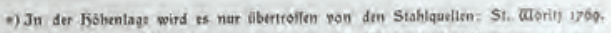

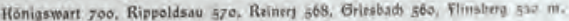

4. Pierwsza strona broszury reklamowej Świeradowa-Zdroju, Archiwum Państwowe we Wrocławiu, Oddział w Kamieńcu Ząbkowickim, Akta miasta Duszniki, Brochuren über Bad Reinerz 1900-1903, nr inw. 2127, s. 437

przestrzennych, poleca „nowe czy niezwykłe, ale przy tym szczególnie oddziałujące środki do wzbudzenia uwagi i zainteresowania"43. Już wówczas zdawano sobie sprawę z atrakcyjności trzeciego wymiaru — dziś, w obliczu technologii

43 APK, akta miasta Duszniki, Brochuren über Bad Reinerz 1900-1903, sygn. 2127. 
cyfrowych, temat ten staje się szczególnie aktualny ${ }^{44}$. Siłę przekazu ikonograficznego akcentuje również w swojej ofercie firma Meisenbach Riffarth \& Co Berlin Graphische Kunstanstalten:

Przedstawienie obrazowe jest tym środkiem propogandowym, który ma moc oddziaływania. Słowo drukowane znika wśród obfitości ogłoszeń, tylko to, co rejestruje oko, pozostaje w wyobrażeniach. Dotyczy to w pierwszej linii zdrojów, kurortów, letnisk, miejscowości wypoczynkowych i sanatoriów, których coraz większa ilość wymaga na czas reklamy, która jest warunkiem sukcesu ${ }^{45}$.

Tego typu argumentacja wśród zachowanych w dawnych aktach miejskich materiałów jest uderzająco częsta i świadczy o intensywności, z jaką wówczas rozwijała się reklama w służbie promocji miejscowości uzdrowiskowych, a szerzej wpisuje się w zjawisko określane mianem ofensywy ikonicznej, która była wynikiem między innymi rozwoju fotografii oraz uprzemysłowienia technik reprodukcyjnych. Powielane na różny sposób od XIX wieku obrazy, sprzedawane w dużych liczbach odbitki graficzne, a z czasem fotografie doprowadziły do sytuacji, w której obraz stał się wszechobecny i zapanował nad masową wyobraźnią ${ }^{46}$.

Wszystkie te działania wizerunkowe równocześnie podparte były rzeczywistą troską o rozwój i jakość oferty turystycznej. Przez cały XIX wiek oraz pierwszą połowę XX wieku trwały rozbudowy poszczególnych uzdrowisk oraz wprowadzane były liczne udogodnienia — zarówno w infrastrukturze miejscowości, jak i zakresie wyposażenia zakładów leczniczych. W 1847 roku we wzniesionym w 1498 roku lądeckim zakładzie Georgenbad (obecnie Jerzy) wprowadzono pierwsze wanny wyłożone płytkami porcelanowymi zamiast wanien drewnianych; kilka lat później wprowadzono również wanny marmurowe. W latach 1877-1880 w Lądku powstał Marienbad, wybudowany przez architekta Hermanna Völkera, w 1912 roku zaś, w związku z odkryciem radioaktywności źródeł termalnych, miasto wzniosło nowoczesne, szeroko reklamowane Radium-Emanatorium. Dwa lata później rozpoczęła się budowa nowego Georgenbad — projekt nowej budowli przygotował rządowy mistrz budowlany (Rudolf?) Balhorn z Kłodzka, a budowę kontynuował budowniczy Goebel z Bystrzycy Kłodzkiej ${ }^{47}$. Przykładem uzdrowiska rozbudowanego zasadniczo w początkach XX wieku jest Polanica. W 1904 roku utworzono tam spółkę akcyjną do zarządzania zdrojami, której celem była rozbudowa i rozwój zdroju. Jej głównym udziałowcem, a później wyłącznym wła-

${ }^{44}$ Por. m.in. P. Kuroczyński, Die Medialisierung der Stadt: analoge und digitale Stadtführer zur Stadt Breslau nach 1945, Bielefeld 2011.

45 APK, akta miasta Duszniki, Brochuren über Bad Reinerz 1904-1909, sygn. 2128, s. 164 165.

46 Zob. M. Komza, Zbiory graficzne we współczesnej cywilizacji obrazu, [w:] Świat w obrazach. Zbiory graficzne w instytucjach kultury - ich typologia, organizacja i funkcje, red. M. Komza, Wrocław 2009, s. 9-18.

47 Bad Landeck/Schlesien. Bilder aus einer deutschen Stadt, red. R. Hauck, Leimen-Heidelberg [1973], s. 200-201. 
ścicielem był Georg Haase, prowadzona była zaś przez Georga Berlita. W 1906 roku zrealizowano pierwszą część rozbudowy zdroju. Architekt i mistrz budowlany Andreas Ernst, właściciel założonego w 1891 roku dużego przedsiębiorstwa budowlanego i biura architektonicznego w Kłodzku z filią w Polanicy, wzniósł nowy dom zdrojowy (obecnie sanatorium Wielka Pieniawa) ze stu trzydziestoma pokojami, własnym zakładem przyrodoleczniczym oraz oświetleniem elektrycznym. Należał on do najokazalszych i najlepiej wyposażonych domów zdrojowych owych czasów, miał tarasy i ogrzewane, przeszklone werandy. Do 1910 roku w okolicach kurortu powstało jeszcze około pięćdziesiąt nowych pensjonató ${ }^{48}$, w tym część z nich została wybudowana przez firmę Ernsta. W latach 1910-1911 pod kierownictwem architektów Felixa Wildego i Paula Rothera powstał okazały, wielofunkcyjny gmach Łazienek Heleny (obecnie Pijalnia Zdrojowa). Wszystkie te budowy podlegały opinii zarządu uzdrowiska, który dbał o estetykę i zachowanie nowoczesnych standardów budowlanych.

W połowie XIX wieku w Dusznikach wznoszono Dom Zdrojowy (obecnie Zakład Przyrodoleczniczy Jan Kazimierz), a już w 1874 roku przystąpiono do modernizacji jego wnętrz, rozpoczynając między innymi budowę nowego domu prysznicowego i łazienek. Pracami kierował wrocławski architekt Wilhelm Rhenius; jemu też uzdrowisko zawdzięczało ogród zimowy (palmiarnię), postawiony jako łącznik między łazienkami a budynkiem natrysków. Budowa trwała do 1885 roku, ale znaczną część obiektu wykorzystywano już od 1876 roku jako cukiernię, salę koncertową i czytelnię prasy. Obiekt wyposażony w oświetlenie elektryczne ogrzewany był nawiewem ciepłego powietrza spod posadzki. Palmiarnię rozebrano w 1910 roku podczas przebudowy całości w Nowy Dom Zdrojowy, rozpoczętej w $1909 \mathrm{roku}^{49}$. Zmiany projektowali i pracami kierowali do 1911 roku Paul Rother i Felix Wilde z Berlina-Charlottenburga. Wśród nowości oraz udogodnień z tego czasu wymienić należy chociażby doprowadzenie do łazienek ciepłej i zimnej oraz mineralnej wody, salę za stanowiskami inhalacyjnymi, poczekalnię z kasami i toaletami, windę elektryczną i centralne ogrzewanie. Modernizacja przeprowadzona w 1936 roku dotyczyła głównie zakładu kąpielowego.

W Świeradowie, w miejscu poprzedniego Domu Źródlanego z 1781 roku, zniszczonego w czasie pożaru 14 grudnia 1895 roku, powstał odbudowany przez Schaffgotschów na podstawie projektu wrocławskiego architekta Karla Grossera dom zdrojowy, który w 1899 roku przyjął pierwszych kuracjuszy. Po odbudowie na parterze budynku mieściły się między innymi salony: gier, muzyczny, taneczny, natomiast na wyższych kondygnacjach — siedemdziesiąt luksusowych pokoi gościnnych. Równocześnie wokół powstaje nowy park zdrojowy. W wybudowanym w 1934 roku przez Paula Schmidta zakładzie kąpieli radoczynnych, dawniej zwanym Radiumbad, mieści się pijalnia wody radoczynnej.

48 Heimatbuch Altheide Bad, Kreis Glatz/Schlesien, red. G. Wenzel, Lingen 1991, s. 167.

49 „Echo des Heuscheuer- und Mense-Gebirges. Reinerzer Stadt-Blatt” 29, 1909, nr 104, APK, akta miasta Duszniki, sygn. 1577, Chronik von Bad Reinerz. 
Najstarsze uzdrowisko na tych ziemiach — Cieplice — w 1904 roku rozbudowuje park zdrojowy ${ }^{50}$. Projektowanych jest również wiele elementów tak zwanej małej architektury, która ma uatrakcyjnić wizualnie uzdrowiskowe promenady. Zaliczają się do niej przede wszystkim kioski meteorologiczne, mające też swój wymiar praktyczny, oraz fontanny: dusznicka, której początki sięgają 1905 roku, a dziś jest jedną z atrakcji miasta; podobnie świeradowska, której projekty z 1909 roku zachowały się w Archiwum Państwowym we Wrocławiu ${ }^{51}$. Również idea mieniącej się kolorami fontanny w Polanicy ma dość starą metrykę — projekty z 1933 roku znajdują się w kamienieckim oddziale wrocławskiego archiwum ${ }^{52}$.

Intensywność inwestycji budowlanych z zakresu upiększania miast nie działa się jednak bez kontroli i starań o ustanowienie standardów technicznych i estetycznych oraz troski o ochronę konserwatorską. Wyrazem tych dążeń były opracowywane w początku XX stulecia statuty dotyczące kształtowania miejskiego wizerunku (Ortsstatuten gegen Veranstaltung des Stadtbildes): od 1909 roku w Szczawnie; od 1911 roku — w Lądku i Dusznikach; od 1913 roku w Kudowie ${ }^{53}$. Ich celem była ochrona wartości kulturowych uzdrowisk. Określały one obszar zdroju, zawierały szczegółowe regulacje dotyczące form zabudowy i przepisy odnośnie do wszystkich zmian w formie budowli, a także wznoszenia małej architektury, jak pawilony, altany, których budowa wymagała specjalnego zezwolenia, oraz zamieszczania reklam, które wymagało zezwolenia policji budowlanej, aby „nie oddziaływać negatywnie na szczególny charakter miejsca i obraz jego ulic". Zakładały także ochronę budowli historycznych i regulowały kwestie techniczno-sanitarne, takie jak obowiązek podłączenia wszystkich budynków do sieci wodnej i elektrycznej.

To nowe, rozbudowane otoczenie mogło stać się areną różnych wydarzeń, zarówno kulturalnych, jak i sportowych, które także były elementem oferty turystycznej. Zawody sportowe, zwłaszcza w sportach zimowych, takich jak skoki narciarskie, zyskujących zainteresowanie w początkach XX wieku, organizowane były przez władze samorządowe, branżę turystyczną i zrzeszenia górskie, które włączyły się w ten sposób w ,szeroko rozumianą promocję nowych form rekreacji” ${ }^{54}$. Uzdrowiska, takie jak Kudowa, Polanica czy Cieplice, słynęly ze swych zdrojowych

50 APW, zespół nr 153, akta majątku Schaffgotschów w Cieplicach, 1312-1945, Sect. II, Fach nr 31, 3 (1611), s. 24; Situationsplan vom Kurpark und Umgebung zu Warmbrunn, około 1904.

51 APW, zespół nr 153, akta majątku Schaffgotschów w Cieplicach, Sect. II, Fach nr 31, 3 (1611).

52 APK, dokumentacja techniczna dotycząca budowy fontanny kolorowej w Polanicy-Zdroju, 1933, sygn. 12.

53 Zob. APK, akta miasta Duszniki, sygn. 1644; ibidem, między innymi s. 23; wycinek z „Salzbrunner Zeitung — Beilage zur Salzbrunner Zeitung” 24.07.1909, artykuł Bekanntmachung für Ober-Salzbrunn. Orts-Statut, s. 44; Ortsstatut gegen Verunstaltung, Landeck 1911, s. 45-46, 54; Ortsstatut zum Schutze des Bades Reinerz gegen Verunstaltung, 1911, s. 103; Ortsstatut gegen Verunstaltung der Gemeinde Kudowa.

54 T. Przerwa, Między lękiem a zachwytem. Sporty zimowe w ślaskich Sudetach i ich znaczenie dla regionu (do 1945 r.), Wrocław 2012, s. 10. 
teatrów i licznych, organizowanych z myślą o kuracjuszach, koncertów, dawanych przez zatrudniane przez zarządy uzdrowisk orkiestry, jak na przykład w Polanicy, gdzie „Kurkapelle” działała od 1906 roku $^{55}$. Wydarzenia te znów zyskiwały plastyczną oprawę w postaci plakatów czy programów; budynki teatrów były częstym motywem nie tylko grafik czy pocztówek, ale pojawiały się również na naczyniach, na przykład teatr w Cieplicach wygrawerowany został na talerzu dekoracyjnym przechowywanym w Państwowych Zbiorach Sztuki w Dreźnie ${ }^{56}$.

Rozwój masowej ikonografii oraz wzmagająca się intensywność ikonosfery wokół fenomenu kultury zdrojowej od XIX do pierwszej połowy XX wieku rozumiane są tutaj jako jeden $\mathrm{z}$ aspektów turystycznej ewolucji uzdrowisk. Zjawisko to widzieć trzeba w wielu kontekstach — przemian społecznych, a szczególnie społecznego odbioru przekazu wizualnego, rozbudowy uzdrowisk, rozwoju medycyny, infrastruktury technicznej i wielu innych. Dotychczasowe badania nad tematem zdrojów koncentrowały się zasadniczo na okresie wcześniejszym ${ }^{57}$, obejmując jeszcze XIX wiek, jednak także pierwsza połowa XX stulecia pozostawiła istotny ślad w przestrzeni turystycznej, a przede wszystkim — co starano się wykazać — wiele świadectw wizualnych. Wszystkie one, począwszy od najstarszych, siedemnastowiecznych voyages pittoresques, po dwudziestowieczne, „nowoczesne” reklamy miejsc, obiektów i wydarzeń, mogą służyć jako podstawa do badań nad kulturą obrazu i jej suwerennych analiz, również z zakresu funkcji perswazyjnej, której ważnym aspektem jest idealizacja przedstawionego świata.

\section{Bibliografia}

\section{Źródła archiwalne}

Archiwum Państwowe we Wrocławiu, akta majątku Schaffgotschów w Cieplicach, 1312-1945

Sect. II, Fach nr 24, 10 (1531).

Sect. II, Fach nr 31, 3 (1611).

Sect. II, Fach nr 31, 10 (1621).

Archiwum Państwowe we Wrocławiu, oddział w Kamieńcu Ząbkowickim, akta miasta Duszniki Akten betr.: Gebirgs-Vereins, t. 3, sygn. 1565.

Bahnhofstr., sygn. 1628.

Brochuren über Bad Reinerz 1894-1899, sygn. 2126.

Brochuren über Bad Reinerz 1900-1903, sygn. 2127.

Brochuren über Bad Reinerz 1904-1909, sygn. 2128.

Brochuren über Bad Reinerz 1910-1912, sygn. 2129.

55 Heimatbuch Altheide Bad, Kreis Glatz/Schlesien, red. G. Wenzel, Lingen 1991, s. 230.

56 Souvenir-Teller, 1840/1850, Staatliche Kunstsammlungen Dresden (SKD), Inv.-nr, 42191.

57 Zob. m.in. J. Dębicki, Kulturowe aspekty sudeckich uzdrowisk obecnego regionu dolnoślaskiego w XVII-XVIII wieku, Torun 2005; idem, Uzdrowiska Ziemi Kłodzkiej do końca XVIII wieku, [w:] Zdroje Ziemi Kłodzkiej: Historia, przyroda, kultura, przyszłość, red. W. Ciężkowski, J. Dębicki, R. Gładkiewicz, Wrocław-Kłodzko 2000, s. 13-32. 
Chronik von Bad Reinerz, sygn. 1577.

Dokumentacja, sygn. 1644.

Dokumentacja techniczna dotycząca budowy fontanny kolorowej w Polanicy-Zdroju, 1933, sygn. 12.

\section{Publikacje}

Bad Kudowa in Schlesien. Das Heilbad für Herz Basedow Nerven- und Frauen Leiden, Görlitz [1931].

Bad Landeck/Schlesien. Bilder aus einer deutschen Stadt, red. R. Hauck, Leimen-Heidelberg [1973].

Bad Salzbrunn in Schlesien. Heilkräftig bei Katarrhen, Asthma Gicht, Nierenleiden, Görlitz [ok. 1930].

Banaś P., Orbis pictus. Świat dawnej karty pocztowej, Wrocław 2005.

Beinert C., Charlottenbrunn als Trink- und Badekur-Anstalt nebst Beschreibung der nächsten Parkanlagen, Charlottenbrunn 1859.

Bower H. de, Advertising Principles, New York 1921.

Brade J., „Piękny widok”: Idealizujące i romantyczne przedstawienia śląskich miast, krajobrazów oraz przemystu od okoto 1800 do 1850/1860 roku, [w:] Podróże w czasie. Dawne widoki Śląska na grafikach z kolekcji Haselbacha [Zeit-Reisen: historische Schlesien-Ansichten aus der Graphiksammlung Haselbach], z tekstami A. Marsch, J. Brade, D. Codogni-Łańcuckiej, A. Herziga, H. Wańka, Wrocław 2007.

Codogni-Łańcucka D., Musée imaginare, [w:] Podróże w czasie. Dawne widoki Ślaska na grafikach z kolekcji Haselbacha [Zeit-Reisen: historische Schlesien-Ansichten aus der Graphiksammlung Haselbach], z tekstami A. Marsch, J. Brade, D. Codogni-Łańcuckiej, A. Herziga, H. Wańka, Wrocław 2007.

Dengler P., Geschichte des Bades Reinerz, Reinerz 1903.

Dengler P., Schlesiche Bädertag, „Allgemeine Deutsche Bäder-Zeitung” 4, 1907, nr 24.

Dębicki J., Kulturowe aspekty sudeckich uzdrowisk obecnego regionu dolnośląskiego w XVII-XVIII wieku, Toruń 2005.

Dębicki J., Uzdrowiska Ziemi Kłodzkiej do końca XVIII wieku, [w:] Zdroje Ziemi Kłodzkiej: Historia, przyroda, kultura, przyszłość, red. W. Ciężkowski, J. Dębicki, R. Gładkiewicz, Wrocław-Kłodzko 2000.

„Die Grafschaft Glatz. Illustrierte Zeitschrift des Glatzes Gebirgsvereins” 9, 1914, nr 2.

Ein Radiumbad in Bad Flinsberrg. Das dritte Radiumbad Deutschland errichtet, „Görlitzer Nachrichten" 9.06.1934.

Gwiazdowska E., Widoki Szczecina. Źródła ikonograficzne do dziejów miast od XIV wieku do 1945, Szczecin 2001.

Heimatbuch Altheide Bad, Kreis Glatz/Schlesien, red. G. Wenzel, Lingen 1991.

Herzig A., Śląsk w pierwszej połowie XX wieku, [w:] Podróże w czasie. Dawne widoki Śląsa na grafikach z kolekcji Haselbacha [Zeit-Reisen: historische Schlesien-Ansichten aus der Graphiksammlung Haselbach], z tekstami A. Marsch, J. Brade, D. Codogni-Łańcuckiej, A. Herziga, H. Wańka, Wrocław 2007.

Ikonografia Dolnego Ślaska: pocztówki, red. i oprac. R. Heś, Z. Bandurska, t. 1. Bagieniec-Rzeczka, t. 2. Sady Górne-Ż́rawina Sudety, Wrocław 2011.

Ikonografia Wrocławia, red. P. Łukaszewicz, oprac. E. Halawa, Wrocław 2008.

Jaworski R., Alte Postkarten als kulturhistorische Quellen, „Geschichte in Wissenschaft und Unterricht" 51, 2000, nr 2.

Komza M., Zbiory graficzne we wspótczesnej cywilizacji obrazu, [w:] Świat w obrazach. Zbiory graficzne w instytucjach kultury - ich typologia, organizacja i funkcje, red. M. Komza, Wrocław 2009.

Góry - Literatura - Kultura 13, 2019

(c) for this edition by CNS 
Konieczny M., Reklama. Poradnik w sprawach nowoczesnej kupieckiej reklamy: podręcznik dla szkót zawodowych. Wiadomości ogólne, podstawy psychologiczne, ogłoszenia gazetowe, list reklamowy, prospekt, broszura, katalog, Poznań 1938.

Kur-Bad Altheide in der Grafschaft Glatz, Provinz Schlesien. Mächtige Kohlensäure-Sprudel und weitere Moorlager gegen Herz-, Stoffwechsel- und Frauenkrankheiten, [Altheide] 1910.

Kuroczyński P., Die Medialisierung der Stadt: analoge und digitale Stadtführer zur Stadt Breslau nach 1945, Bielefeld 2011.

Langer O., Zasady ogłaszania, Warszawa 1927.

Larned L., Illustration in Advertising, New York 1920.

Marsch A., Popularność uzdrowisk i pamiątki, [w:] Dioramen. 3D-Schaublider der 19. Jahrhundert aus Schlesien und Böhmen / Dioramy. Trójwymiarowe obrazy XIX wieku ze Ślaśka i Czech, Hamburg 2005.

Marsch A., Widoki Ślaska od 1493 roku do końca XIX wieku a kolekcja Haselbacha, [w:] Podróże w czasie. Dawne widoki Śląska na grafikach z kolekcji Haselbacha [Zeit-Reisen: historische Schlesien-Ansichten aus der Graphiksammlung Haselbach], z tekstami A. Marsch, J. Brade, D. Codogni-Łańcuckiej, A. Herziga, H. Wańka, Wrocław 2007.

Mosch C.F., Die Heilquellen Schlesiens und der Grafschaft Glatz, Breslau-Leipzig 1821.

Mosch C.F., Wanderungen durch das Riesen- und Iser-Gebirge und durch die ihnen benachbarten Thäler: ein Leitfaden für Reisende durch diese Gegenden, Warmbrunn 1845.

Mrugalska-Banaszak M., Miejska ikonosfera na drukach reklamowych $w$ widokami Poznania (1835-1939), Poznań 2012.

Porębski M., Ikonosfera, Warszawa 1972.

Preiß B., Der Kurort Warmbrunn, seine warmen Schwefelquellen und die ihren zugehörigen Heilanstalten. Ein Führer und Leitfaden für den Kurgast, mit besonderer Rücksicht auf Diätik, Wrocław 1850.

Przerwa T., Między lękiem a zachwytem. Sporty zimowe w śląskich Sudetach i ich znaczenie dla regionu (do 1945 r.), Wrocław 2012.

Schmidt W.L., Die Ruinen von Kynast, Hirschberg [ok. 1823].

Schmidt W.L., Warmbrunn und seine Heilquellen, Hirschberg 1821.

Sudeten Album. Die Schlesische Bäder und Ihre Umgebung. Nach Natur gezeichnet von F. Koska, Wrocław 1846-1862. 